\title{
Efecto de dos diluyentes sobre la tasa de preñez por inseminación artificial laparoscópica en ovinos.
}

\author{
Cely, L.D.; Jaramillo, C.X.; Fonseca, M.J \\ Grupo de Investigación en Ciencias Animales, Laboratorio de Reproducción Animal, Programa de Medicina \\ Veterinaria, Cátedra de Reproducción Animal, Universidad de Pamplona, Facultad de Ciencias Agrarias, \\ Santander, Colombia. Email: xavier.jaramillo@unipamplona.edu.co
}

\begin{abstract}
Resumen
Cely, L.D.; Jaramillo, C.X.; Fonseca, M.J.: Efecto de dos diluyentes sobre la tasa de preñez por inseminación artificial laparoscópica en ovinos. Rev. Vet. 32:2, 221-224, 2021. El objetivo del estudio fue evaluar dos diluyentes comerciales para el congelamiento de semen ovino y determinar su efecto en la tasa de preñez al ser utilizados en inseminación artificial laparoscópica. El semen utilizado fue de un carnero Dorper adulto, cuyo eyaculado fue dividido en dos: una alícuota fue diluida con un diluyente comercial con base de lecitina de soya y la otra con un diluyente con base de yema de huevo. El semen fue criopreservado (100 x $10^{6}$ espermatozoides móviles) y cada tipo de dilución fue utilizado para inseminar 15 ovejas. Las hembras fueron sincronizadas con esponjas intravaginales e inseminadas vía laparoscópica. El diagnóstico de preñez por ecografía se hizo a los 60 días del servicio. Los resultados indicaron una tasa de preñez de $85 \%$ con semen diluido en base de lecitina de soya y $78 \%$ con yema de huevo, no habiendo diferencias significativas entre tratamientos. Se concluye que la tasa de preñez obtenida con los dos diluyentes utilizados es similar, por lo cual ambos ofrecen los mismos beneficios a la hora de implementarlos en un programa reproductivo para la especie ovina, mediante inseminación artificial laparoscópica.
\end{abstract}

Palabras clave: criopreservación, espermatozoides, gestación, ovinos, ultrasonografía.

\begin{abstract}
Cely, L.D.; Jaramillo, C.X.; Fonseca, M.J.: Effect of two diluents on pregnancy rate by laparoscopic artificial insemination in sheeps. Rev. Vet. 32: 2, 221-224, 2021. The aim of this study was to evaluate two commercial diluents for the freezing of sheep semen and determine their effect on the pregnancy rate when used in artificial laparoscopic insemination. The semen used was from an adult Dorper ram, whose ejaculate was divided in two and one aliquot was diluted with a commercial diluent based on soy lecithin and the other aliquot with a commercial diluent based on egg yolk. The semen was cryopreserved $(100 \mathrm{x}$ $10^{6}$ motile sperm) and each type of dilution was used to inseminate 15 sheep. The females were synchronized with intra-vaginal sponges and inseminated via laparoscopic. The diagnosis of pregnancy by ultrasound was made 60 days after the service. The results indicated a pregnancy rate of $85 \%$ with semen diluted with soy lecithin and $78 \%$ with egg yolk, with no significant differences between treatments. Conclusions: pregnancy rate obtained with the two diluents was similar; therefore these offer the same benefits to use in ovine reproductive programs, by laparoscopic artificial insemination.
\end{abstract}

Key words: cryopreservation, sperm, pregnancy, sheep, ultrasound.

\section{INTRODUCCION}

La inseminación artificial (IA) es una de las prácticas de manejo más valiosas para los productores de las especies ovinas en los programas de reproducción que emplean semen descongelado $3,17,18,22$.

El proceso de inseminación artificial en ovinos supone dos limitantes que revisten gran importancia dentro de esta área, uno de ellos está directamente relacionado con la anatomía tortuosa del cuello uterino, que no permite el paso adecuado o fácil de la zona para inseminar en la especie ovina, la cual a diferencia de otras especies como la bovina, porcina y equina, no presentan dicho inconveniente.

Se han diseñado catéteres específicos adaptados a la luz tortuosa del cuello uterino de los ovinos, para tratar de atravesar esa "barrera cervical" 2, 12, 14, 24. Como alternativa, se emplea la técnica de inseminación laparoscópica para depositar él semen descongelado inmediatamente al interior de los cuernos ${ }^{13}$

El otro inconveniente radica en la baja capacidad de fertilización de los espermatozoides, porque sufren alteraciones debidas al estrés oxidativo producido por el choque térmico ${ }^{20}$. La anterior situación la expresan 
estudios donde se argumenta que los espermatozoides de ovinos son más susceptibles que los espermatozoides de bovinos al procedimiento de congelación y descongelación, técnica que conlleva la reducción del número de células móviles ${ }^{23}$.

Como ventajas de la IA se pueden enlistar que las tasas de preñez empleando semen descongelado son bastante buenas comparadas a la inseminación transcervical ${ }^{20}$. Por otra parte es factible emplear dosis inseminantes con menor concentración de esperma. Para lo anterior se requiere de personal capacitado en la estrategia anestésica, conocimiento y manejo del equipo y desde luego la anatomía de la especie a trabajar ${ }^{13}$.

Actualmente algunos estudios describen nuevos métodos para el depósito intrauterino transcervical de semen, empleando para ello una incisión quirúrgica de los pliegues cervicales, técnica que se constituye en un procedimiento novedoso permitiendo tasas de preñez satisfactorias en toda la vida del paciente.

La IA es importante porque de su eficacia depende el progreso genético del hato $\mathrm{y}$, asimismo, la eficiencia reproductiva. Sin embargo, la IA con semen congelado no es muy difundida en la especie ovina, debido principalmente a las bajas tasas de fertilidad que son obtenidas $^{22}$.

Los espermatozoides de ovinos son más susceptibles que los espermatozoides bovinos al procedimiento de congelación y descongelación, técnica que conlleva la reducción del número de células móviles ${ }^{23}$.

Los daños producidos en los espermatozoides durante el proceso de criopreservación podrían ser parcialmente obviados usando diluyentes adecuados, tales como yema de huevo, pese a su limitante de ser un medio óptimo para bacterias y endotoxinas. No obstante, ha reportado tener un efecto tóxico en los espermatozoides de las especies bufalina, ovina y caprina ${ }^{1}$. Así mismo, se indica que contiene trazas de hormonas y sus precursores, que podrían disminuir la capacidad de fertilización de los espermatozoides ${ }^{11}$.

Los diluyentes libres de elementos de origen animal que contienen lecitina de soya tienen un efecto crioprotector por su baja viscosidad, poseen menos residuos y alto contenido de fosfolípidos, al igual que la yema de huevo ${ }^{9}$.

Se reporta que la lecitina de soja (1-2\%) tiene la ventaja frente a los diluyentes convencionales (yema de huevo y leche) de ser un compuesto libre de patógenos, incluso cuando se hace el almacenamiento a baja temperatura de semen ovino; de allí que los diluyentes comerciales actuales contienen proteína vegetal (lecitina de soya) como protectores en la criopreservación ${ }^{6,10}$.

A pesar de haberse empleado una gran cantidad de diluyentes para la congelación de semen ovino, no existe una metodología que proporcione datos sobre los mejores resultados para el semen descongelado ${ }^{21}$.

El objetivo de esta investigación fue evaluar dos diluyentes comerciales utilizados rutinariamente en la especie bovina para el congelamiento de semen ovino y determinar los resultados en términos de tasas de pre- ñez al ser utilizados en inseminación artificial laparoscópica.

\section{MATERIAL Y MÉTODOS}

Los procedimientos de evaluación, dilución y congelación del material seminal ovino fueron llevados a cabo en el Laboratorio de Reproducción Animal, perteneciente a la granja Villa Marina de la Universidad de Pamplona, Colombia.

\section{Colecta y congelación de semen}

Se seleccionó un ovino Dorper de 1,5 años y $60 \mathrm{~kg}$ de peso. El semen fue colectado mediante electroeyaculador Electro Jac-5. La calidad seminal fue evaluada tal como lo efectuaron acertadamente otros investigadores ${ }^{7}$, considerando las características macroscópicas (volumen, color, olor, aspecto) y las características microscópicas (motilidad masal, motilidad individual, concentración, morfoanomalías y porcentaje de vivos y muertos) empleando un microscopio óptico (Scientific). El semen fue diluido utilizando dos diluyentes comerciales, uno con base a lecitina de soya (Andromed) y otro con base a yema de huevo (Tryladil). En ambos casos, el semen fue criopreservado mediante la congeladora de semen Cryogen que se observa en la Figura $I$.

\section{Sincronización de celos}

Para los procesos de sincronización e inseminación artificial laparoscópica fueron seleccionadas 30 hembras de la raza ovino de pelo colombiano (OPC), con edad promedio de 20 meses y peso de $40 \mathrm{~kg}$, ubicadas en el municipio de Labateca Norte (Santander, Colombia). Las ovejas fueron sincronizadas mediante esponja intravaginal (Progespon) impregnada con 60 $\mathrm{mg}$ de acetato de medroxi-progesterona. Las esponjas fueron mantenidas durante siete días para luego ser retiradas, aplicándose un análogo de prostaglandina $F 2$ alfa a una dosis total de $0,2 \mathrm{mg}$ (Estrumate) y $200 \mathrm{UI}$ de eCG-gonadotropina coriónica equina (Novormon),

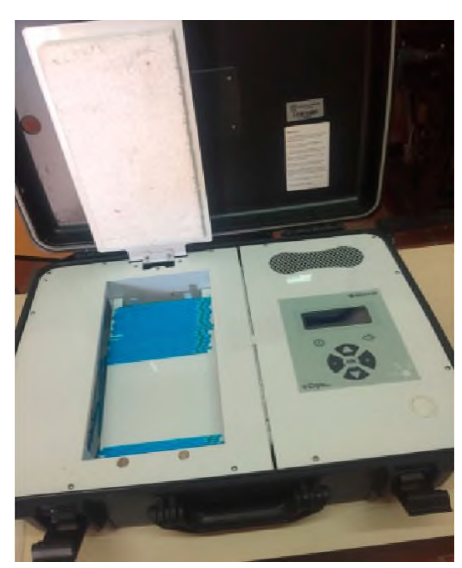

Figura 1. Congeladora de semen Cryogen ${ }^{\circledR}$ modelo Neovet. 


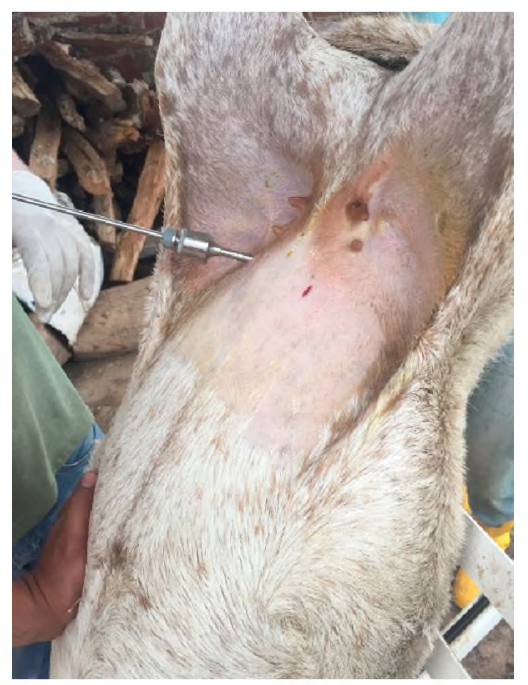

Figura 2. Introducción de la cámara a través del trocar.

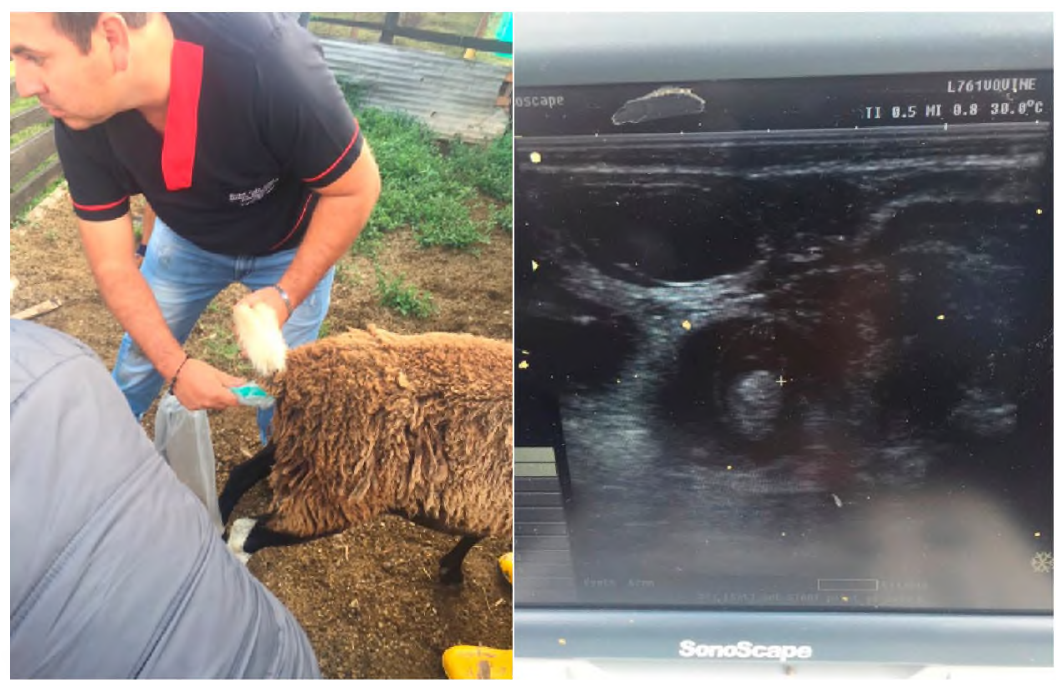

Figura 3. Exploración rectal ecográfica con ecógrafo Sonoscape para el diagnóstico de preñez vía intramuscular. La inseminación se llevó a cabo a las 52 horas de las aplicaciones de prostaglandina y eCG.

\section{Inseminación artificial por laparoscopía}

Para la pre-anestesia se utilizó xilacina al 2\% a dosis de $0,05 \mathrm{mg} / \mathrm{kg}$, vía intramuscular. Posteriormente, cada hembra fue posicionada en la camilla de cirugía, sujetando las cuatro extremidades y aplicando $5 \mathrm{ml} \mathrm{de}$ lidocaína al 2\% (Roxicaina) por vía subcutánea alrededor del lugar de incisión. Para la LA laparoscópica se realizaron dos pequeñas incisiones de $5 \mathrm{~cm}$ craneales a la base de la glándula mamaria y $4 \mathrm{~cm}$ lateral a la línea alba. Luego fue introducida, por una de las incisiones, una Aguja de Veress conectada a la máquina insufladora de $\mathrm{CO}_{2}$ (L'care) para introducir el gas en la cavidad abdominal. Una vez retirada la Aguja de Veress se colocaron trócares de $5 \mathrm{~mm}$. Por una de las incisiones se introdujo la cámara y por la otra la pinza Maryland para ubicar los cuernos uterinos, cómo puede apreciarse en la Figura 2. Una vez identificados se retiró la pinza y se introdujo la pipeta de Robertson (Minitube) con el semen, depositando por punción 0,25 ml en cada cuerno uterino. Finalmente, se retiraron la cámara y la pipeta, se hizo presión en el abdomen para expulsar el $\mathrm{CO}_{2}$ por los trocares, y el paciente fue llevado al área de recuperación y posicionado en decúbito lateral derecho, aplicándosele una crema cicatrizante (Neobest) en las incisiones y una dosis $(5 \mathrm{mg} / \mathrm{kg})$ de oxitetraciclina L.A. (Erma) vía intramuscular.

\section{Descongelamiento del semen}

Para la inseminación, las pajillas de semen fueron retiradas del termo de nitrógeno líquido (Taylor Wharton) y fueron depositadas en un termo descongelador por 50 segundos a $37^{\circ} \mathrm{C}$. El semen descongelado fue vertido en un tubo Eppendorf de $2 \mathrm{ml}$. Se evaluó la motilidad progresiva al microscopio óptico para determi- nar la viabilidad del semen, y posteriormente se cargó el semen en la pipeta de Robertson para realizar la IA.

\section{Tasa de preñez}

El diagnóstico de gestación por ecografía se realizó a los 60 días de la IA. Se utilizó un ecógrafo (Sonoscape) con transductor rectal cubierto por una manga de palpación, como se observa en la Figura 3.

\section{Análisis estadístico}

Los datos obtenidos fueron analizados aplicando la prueba de Chi cuadrado ( $\chi 2)$ y los correspondientes coeficientes de asociación. Todos los resultados fueron considerados estadísticamente significativos para un valor de $\mathrm{p} \leq 0,05$.

\section{RESULTADOS Y DISCUSIÓN}

La tasa de preñez utilizando como diluyente del semen a la lecitina de soya (Andromed) fue de $85 \%$ $(12 / 15)$, mientras que la tasa de preñez utilizando como diluyente a la yema de huevo (Triladyl) fue de $78 \%$ (11-15), no habiendo diferencia estadística significativa entre los tratamientos. Los resultados de la prueba Chi-cuadrado indicaron que las variables fueron independientes $(p=0,6217)$, es decir, que la preñez fue independiente del diluyente utilizado.

Tales hallazgos concuerdan con to reportado en otro estudio en el cual se obtuvo tasa de preñez del $85 \%$ utilizando lecitina de soya y del $78 \%$ con yema de huevo ${ }^{9}$. Asímismo, los resultados concuerdan con otra publicación en la que se reportó $42 \%$ de preñez para yema de huevo y $44 \%$ para lecitina de soya ${ }^{15}$. Diversos estudios han reportado porcentajes de preñez entre $\mathbf{4 5}$ y $80 \%$, obtenidos por IA artificial laparoscópica $3,4,8,19$.

El $78 \%$ de preñez obtenido en este estudio con el diluyente a base de yema de huevo, corrobora la afir- 
mación de que el uso de este diluyente of rece mejor motilidad y mayor fertilidad con semen congelado/descongelado ${ }^{6}$.

No obstante, en otro estudio se reportó una tasa de preñez de $64,7 \%{ }^{16}$, pudiendo deberse esta diferencia a que en dicho estudio se utilizó una concentración de 40 x $10^{6}$ espermatozoides móviles, mientras que en el presente estudio se trabajó con $100 \times 10^{6}$ espermatozoides móviles. Las altas tasas de preñez obtenidas en este estudio podrían deberse al uso de esponjas impregnadas con progesterona, ya que éstas favorecen el desarrollo y fertilización del ovocito ${ }^{5}$.

No obstante, el objetivo de este estudio fue determinar si existen diferencias en cuanto a las tasas de preñez entre los dos diluyentes evaluados, lo cual fue confirmado al no existir diferencias estadísticamente significativas entre las tasas de preñez obtenidas con ambos.

\section{CONCLUSIÓN}

La tasa de preñez obtenida con los dos diluyentes utilizados fue similar, por lo tanto ambos ofrecen los mismos beneficios a la hora de implementarlos en un programa reproductivo para la especie ovina, mediante inseminación artificial laparoscópica.

\section{REFERENCIAS}

1. Aboagla EM, Terada T. 2004. Effects of egg yolk during the freezing step of cryo-preservation on the viability of goat spermatozoa. Theriogenology 62: 1160-1172.

2. Álvarez $\mathbf{M}$ et al. 2012. Design and in vivo evaluation of two adapted catheters for intrauterine transcervical insemination in sheep. Anim Reprod Sci 131: 3-4, 153-159.

3. Anel L et al. 2005. Factors influencing the success of vaginal and laparoscopic artificial insemination in churra ewes: a field assay. Theriogenology 63: 4, 1235-1247.

4. Avendaño RL et al. 2007. Reproduction performance of Pelibuey ewes in response to estrus synchronization and artificial insemination in northwestern Mexico. JAnim Vet $A d v$ 6: 807-812

5. Bari $\mathbf{F}$ et al. 2001. The repeatability of super-ovulatory response and embryo recovery in sheep. Theriogenology 56: $147-155$.

6. Cámara DR, Guerra MM. 2011. Refrigeração e criopreservação do sêmen ovino: danos inerentes à técnica e influencia da suplementação do meiocom antioxidantes sobre a qualidade espermática. Rev Bras Reprod Anim 5: 33-40.

7. Evans G, Maxwell WM. 1990. Inseminación artificial de ovejas y cabras, Editorial Acriba, Zaragoza, pag. 204.

8. Flores JP et al. 2017. Evaluación de la utilización de semen congelado y refrigerado en la inseminación artificial por laparoscopía en la especie ovina. AICA 9: 41-47.

9. Fukui Y, Kohno H, Togari T, Hiwasa M, Okabe K. 2008. Fertility after artificial insemination using a soybean-based semen extender in sheep. $J$ Reprod Develop 54: 286-289.
10. Hernández L et al. 2014. Efecto de dos diluyentes a base de lecitina de soya sobre parámetros morfométricos en semen caprino. SENNOVA (Sistema de investigación, desarrollo tecnológico e innovación), 1: 30-43.

11. Herold FC, Haas K, Colenbrander B, Gerber D. 2006 Comparison of equilibration times when freezing epididymal sperm from African buffalo (Syncerus caffer) using Triladyl or AndroMed. Theriogenology 66: 1123-1130.

12. Kaabi M et al. 2006. Influence of breed and age on morphometry and depth of inseminating catheter penetration in the ewe cervix. Theriogenology 66: 1876-1883.

13. Kershaw CM et al. 2005. The anatomy of the sheep cervix and its influence on the trans-cervical passage of an inseminating pipette into the uterine lumen. Theriogenology 64: 1225-1235.

14. Macías A et al. 2017. Technical note. A new device for cervical insemination of sheep-design and field test. $J$ Anim Sci 95: 5263-5269.

15. Masoudi $\mathrm{R}$ et al. 2017. Fertility response of artificial insemination methods in sheep with fresh and frozenthawed semen. Cryobiology 74: 77-80.

16. Mellisho E, Terrel W. 2007. Tasa de no retorno después de inseminación intrauterina vía laparoscópica con semen congelado de carneros australianos. Sitio Arg Prod Anim (APPA-ALPA), Cusco, Perú.

17. Pau S et al. 2019. Surgery on cervical folds for transcervical intrauterine artificial insemination with frozen-thawed semen enhances pregnancy rates in the sheep. Theriogenology 1: 126, 28-35.

18. Pau S et al. 2020. Reproductive performance following transcervical insemination with frozen thawed semen in ewes submitted to surgical incision of cervical folds (SICF). Animals 10: 1, 108.

19. Paulenz $\mathbf{H}$ et al. 2004. Fertility results after different thawing procedures for ram semen frozen in minitubes and mini straws. Theriogenology 61: 1719-1727.

20. Salamon S, Maxwell WM. 1995a. Frozen storage of ram semen. I. Processing, freezing, thawing and fertility after cervical insemination. Anim Reprod Sci 37: 185-249.

21. Salamon S, Maxwell WM. 1995b. Frozen storage of ram semen II. Causes of low fertility after cervical insemination and methods of improvement. Anim Reprod Sci 38 : 1-36.

22. Salamon S, Maxwell WM. 2000. Storage of ram semen. Anim Reprod Sci 62: 77-111.

23. Watson PF. 2000. The causes of reduced fertility with cryo-preserved semen. Anim Reprod Sci 60: 481-492.

24. Wulster MC, Lewis GS. 2002. Development of a new trans-cervical artificial insemination method for sheep: Effects of a new trans-cervical artificial insemination catheter and traversing the cervix on semen quality and fertility. Theriogenology 15: 58(7), 1361-1371. 